\title{
Calcifying Fibrous Tumor
}

National Cancer Institute

\section{Source}

National Cancer Institute. Calcifying Fibrous Tumor. NCI Thesaurus. Code C6488.

A benign well-circumscribed paucicellular lesion arising from the soft tissues. It is

characterized by the presence of fibroblasts, lymphoplasmacytic infiltrates, collagenous stroma formation, psammoma bodies, and dystrophic calcifications. 